\title{
Photoswitchable Hopping Transport in Molecular Wires 4 nm in Length
}

\author{
Davood Taherinia $^{\dagger}$, C. Daniel Frisbie ${ }^{*}, *$ \\ ${ }^{\dagger}$ Department of Chemistry, ${ }^{\star}$ Department of Chemical Engineering and Materials Science, \\ University of Minnesota, Minneapolis, Minnesota 55455, United States
}

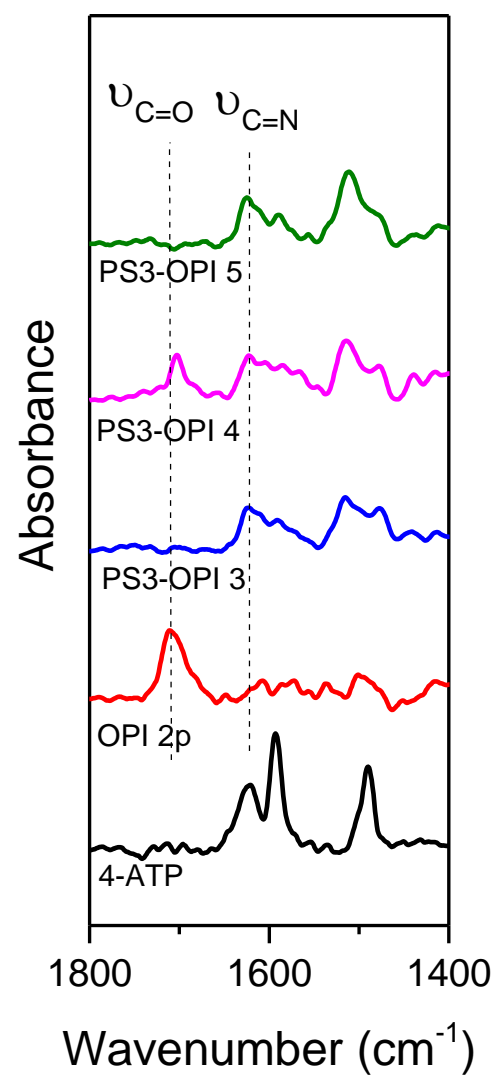

Figure S1. RAIRS spectra corresponding to the stepwise growth of the PS3-OPI 5 wire on Au surface. Dashed lines specify the positions of the imine stretches $\left(\mathrm{C}=\mathrm{N}, 1620 \mathrm{~cm}^{-1}\right)$, and carbonyl stretches $\left(\mathrm{C}=\mathrm{O}, 1704 \mathrm{~cm}^{-1}\right)$. 


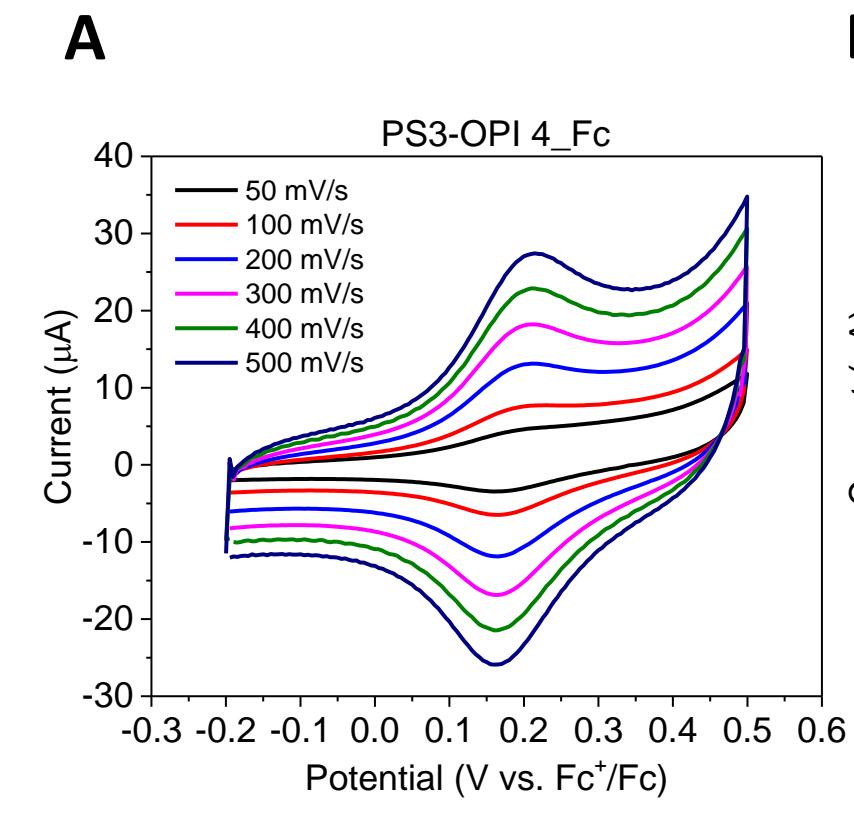

B
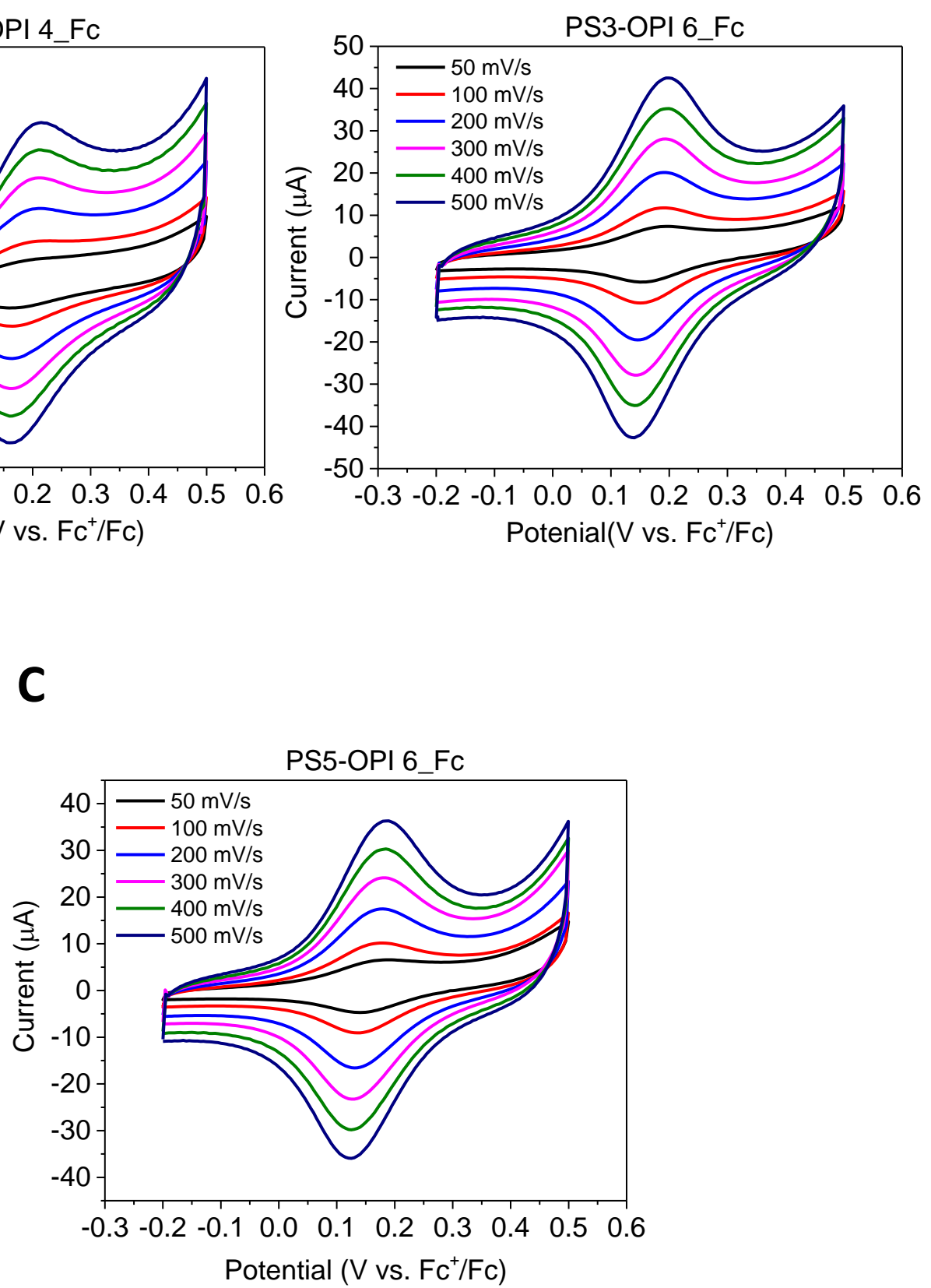

Figure S2. Cyclic voltammograms of (A) PS3-OPI 4_Fc, (B) PS3-OPI 6_Fc, and (C) PS5-OPI 6_Fc molecular wires collected at different sweep rates. 
Table S1. Surface coverages $(\Gamma)$ of the PS-OPI_Fc wires calculated at sweep rates of 100, 200, 300 , and $400 \mathrm{mV} / \mathrm{s}$.

\begin{tabular}{lcccc}
\hline Monolayer & $\begin{array}{l}\Gamma @ 100 \mathrm{mV} / \mathrm{s} \\
\left(\mathrm{molecules} / \mathrm{nm}^{2}\right)\end{array}$ & $\begin{array}{c}\Gamma @ 200 \mathrm{mV} / \mathrm{s} \\
\left(\text { molecules } / \mathrm{nm}^{2}\right)\end{array}$ & $\begin{array}{c}\Gamma @ 300 \mathrm{mV} / \mathrm{s} \\
\left(\text { molecules } / \mathrm{nm}^{2}\right)\end{array}$ & $\begin{array}{c}\Gamma @ 400 \mathrm{mV} / \mathrm{s} \\
\left(\mathrm{molecules} / \mathrm{nm}^{2}\right)\end{array}$ \\
\hline PS3-OPI 4_Fc & 0.25 & 0.30 & 0.33 & 0.30 \\
PS3-OPI 6_Fc & 0.61 & 0.61 & 0.62 & 0.59 \\
PS5-OPI 6_Fc & 0.65 & 0.63 & 0.61 & 0.61 \\
\hline
\end{tabular}

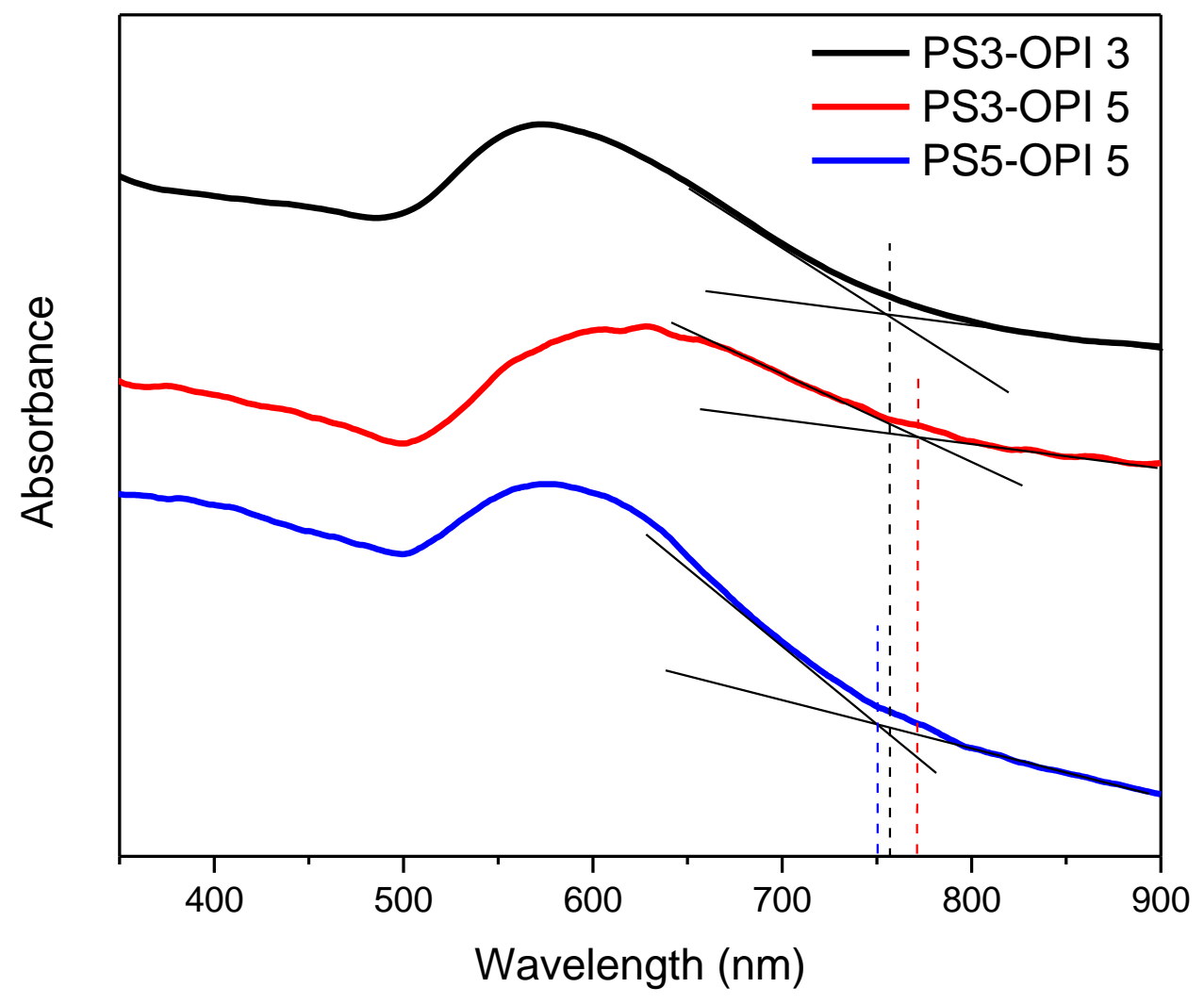

Figure S3. UV-Vis absorption spectra of the PS-OPI molecular wires. The curves are offset in Y direction for clarity. The onset of absorption, indicated by dashed line, was determined for each curve from the intersection of the two solid lines as depicted above. 
A

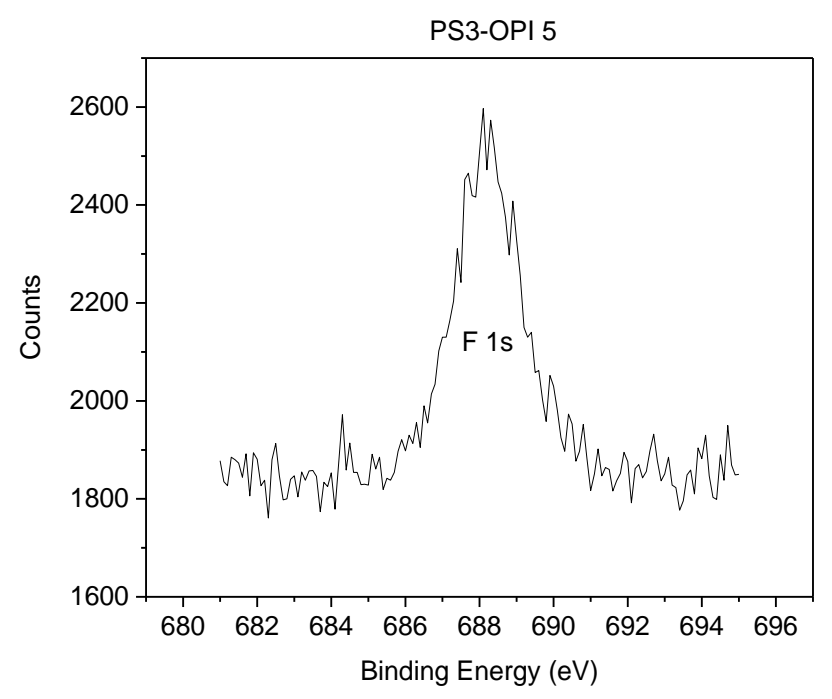

B

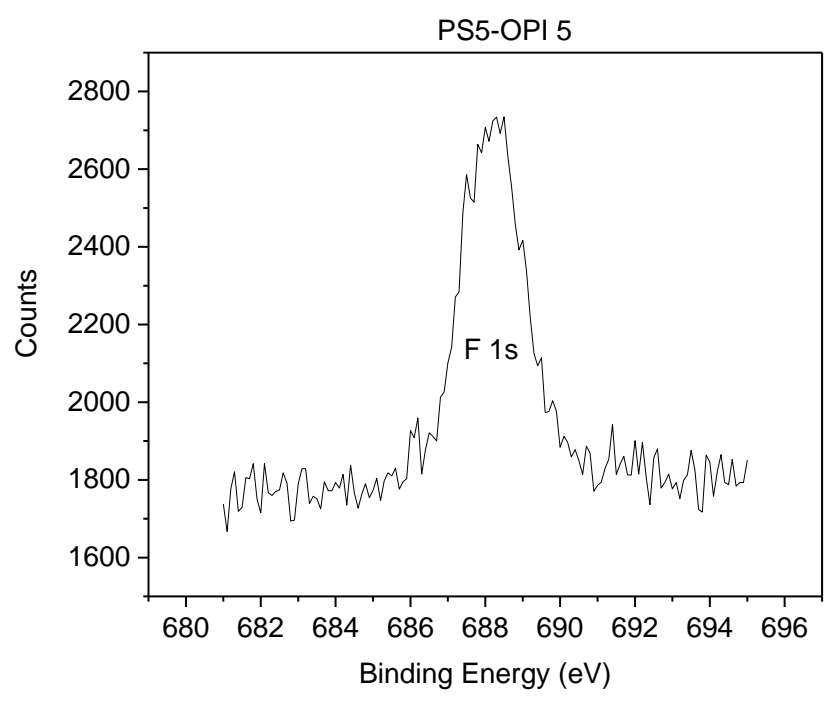

Figure S4. X-ray photoelectron spectra of F 1s core level for (A) PS3-OPI 5 and (B) PS5-OPI 5 molecular wires. 